\title{
A apropriação de noções culturais pela criança: uma experiência de significação na língua-discurso
}

\author{
Carmem Luci da Costa Silva \\ Giovane Fernandes Oliveira
}

Submetido em 11 de setembro de 2016.

Aceito para publicação em 16 de dezembro de 2016.

Cadernos do IL, Porto Alegre, n. ${ }^{\circ}$ 52, dezembro de 2016. p. 402-420

\section{POLÍTICA DE DIREITO AUTORAL}

Autores que publicam nesta revista concordam com os seguintes termos:

(a) Os autores mantêm os direitos autorais e concedem à revista o direito de primeira publicação, com o trabalho simultaneamente licenciado sob a Creative Commons Attribution License, permitindo o compartilhamento do trabalho com reconhecimento da autoria do trabalho e publicação inicial nesta revista.

(b) Os autores têm autorização para assumir contratos adicionais separadamente, para distribuição não exclusiva da versão do trabalho publicada nesta revista (ex.: publicar em repositório institucional ou como capítulo de livro), com reconhecimento de autoria e publicação inicial nesta revista.

(c) Os autores têm permissão e são estimulados a publicar e distribuir seu trabalho online (ex.: em repositórios institucionais ou na sua página pessoal) a qualquer ponto antes ou durante o processo editorial, já que isso pode gerar alterações produtivas, bem como aumentar o impacto e a citação do trabalho publicado.

(d) Os autores estão conscientes de que a revista não se responsabiliza pela solicitação ou pelo pagamento de direitos autorais referentes às imagens incorporadas ao artigo. A obtenção de autorização para a publicação de imagens, de autoria do próprio autor do artigo ou de terceiros, é de responsabilidade do autor. Por esta razão, para todos os artigos que contenham imagens, o autor deve ter uma autorização do uso da imagem, sem qualquer ônus financeiro para os Cadernos do IL.

\section{POLÍTICA DE ACESSO LIVRE}

Esta revista oferece acesso livre imediato ao seu conteúdo, seguindo o princípio de que disponibilizar gratuitamente o conhecimento científico ao público proporciona sua democratização.

http://seer.ufrgs.br/cadernosdoil/index

Terça-feira, 27 de dezembro de 2016 


\title{
A APROPRIAÇÃO DE NOÇÕES CULTURAIS PELA CRIANÇA: UMA EXPERIÊNCIA DE SIGNIFICAÇÃO NA LÍNGUA-DISCURSO
}

\author{
THE APPROPRIATION OF CULTURAL NOTIONS BY \\ CHILDREN: AN EXPERIENCE OF SIGNIFICATION ON \\ LANGUAGE-DISCOURSE
}

\author{
Carmem Luci da Costa Silva ${ }^{1}$ \\ Giovane Fernandes Oliveira ${ }^{2}$
}

\begin{abstract}
RESUMO: Este artigo objetiva analisar a apropriação de noções culturais pela criança como uma experiência de significação na língua-discurso. A partir da Teoria da Enunciação de Benveniste (2005; 2006) e da Teoria Enunciativa da Aquisição da Linguagem de Silva (2007; 2009), são analisados três fatos enunciativos de uma criança acompanhada longitudinalmente dos onze meses aos três anos e quatro meses. Em cada um desses fatos, observa-se como a criança se apropria da noção de susto como fato de cultura constitutivo da sociedade humana. Os resultados da análise sugerem que a significação de assustar (assustar e ser assustado) é determinada, em cada fato enunciativo, pela operação de aquisição ao qual este pertence: o primeiro fato é determinado pelo efeito do preenchimento de lugares enunciativos na operação de intersubjetividade; o segundo fato é determinado pela nomeação relacionada a um duplo movimento de dizer-mostrar na operação de referência; o terceiro fato é determinado pelo relato e pela projeção de ações pela criança na operação de sua inscrição enunciativa na língua-discurso.
\end{abstract}

PALAVRAS-CHAVE: aquisição da linguagem; enunciação; cultura; significação.

ABSTRACT: This article aims to analyze the appropriation of cultural notions by children as an experience of signification on language-discourse. Based on Benveniste's Enunciation Theory (2005; 2006) and Silva's Language Acquisition Enunciative Theory (2007; 2009), three enunciative facts of a child longitudinally monitored from eleven months to three years and four months old were analyzed. In each of these facts, the process in which the child appropriates the notion of fright as a culture within human society is observed. The results suggest that the signification of frightening (to fright and to be frightened) is determined, in each enunciative fact, by the acquisition operation to which it belongs: the first fact is determined by the effect of enunciative places'filling at the intersubjective operation; the second fact is determined by the nomination related to a double movement of say-show at the referencing operation; the third fact is determined by the narration and the projection of actions by the child in the operation of your own enunciative inscription on language-discourse.

KEYWORDS: language acquisition, enunciation, culture, signification

1 Professora de Língua Portuguesa do Instituto de Letras e do Programa de Pós-Graduação em Letras da Universidade Federal do Rio Grande do Sul (UFRGS), doutora em Estudos da Linguagem pela mesma instituição. E-mail: clcostasilva@hotmail.com.

2 Graduando em Licenciatura em Letras, com ênfase em Língua Portuguesa, Língua Francesa e suas Literaturas, pela Universidade Federal do Rio Grande do Sul (UFRGS), bolsista de iniciação científica PIBIC-CNPq. E-mail: giovane.oliveira@ufrgs.br. 


\section{Introdução}

"A linguagem da criança sempre provocou especulações diversas entre leigos ou estudiosos do assunto." Essa constatação de Scarpa (2001, p. 203) é atestada pelo interesse de diferentes áreas do conhecimento pelo tema aquisição da linguagem. É o caso dos diaristas, que produziram estudos conhecidos como "biografias de bebês" (INGRAN, 1989), com contribuições empíricas e descritivas sobre o tema, e também é o caso de muitos campos - como a Linguística, a Psicolinguística e a Psicologia do Desenvolvimento -, que, ao se interessarem pelo tema, fomentaram um saber teórico sobre como a criança adquire a sua língua materna, conforme aponta Silva (2009).

As preocupações em torno de como a criança se torna falante de uma língua fazem parte das problemáticas de linguistas, como Émile Benveniste, que propõem uma reflexão sobre linguagem como indissociável do homem. Pensar o homem na língua, axioma de sua teorização e título da quinta parte dos Problemas de Linguística Geral I e II, requer pensar o nascimento desse homem na linguagem. Por isso, o linguista indaga: "Cada locutor fabrica sua língua, como ele a fabrica? Esta é uma pergunta essencial, já que ela domina o problema da aquisição da linguagem" (BENVENISTE, 1974/2005, p. 18). Inserido nessa problemática, defende: "E se digo que o homem não nasce na natureza, mas na cultura, é que toda criança em todas as épocas [...] aprende necessariamente com a língua os rudimentos de uma cultura" (BENVENISTE, 1974/2005, p. 23).

O problema de aquisição da linguagem, em Benveniste, situa-se no fato de que a criança encontra um homem falando com outro homem no mundo e esse encontro lhe possibilita se integrar à sua língua, em uma integração necessária com a significação, porque o próprio de cada língua, enquanto manifestação da propriedade simbólica da linguagem, é significar. Embora a aquisição da linguagem como um dos problemas de investigação pareça ser tangencial na obra do autor, se tomarmos a sua visada antropológica do homem, na interdependência com a linguagem em sua propriedade essencial de significação, esse fenômeno pode ser visto como central.

Gérard Dessons (2006, p. 10), em Émile Benveniste, l'invention du discours, diz que, "[e]m Benveniste, a arte de pensar é inicialmente a arte do problema" problematização como um modo de pensar é adotada pelo autor em todos os seus textos, comparecendo já no título de suas obras mais célebres: Problemas de Linguística Geral I (PLG I) e Problemas de Linguística Geral II (PLG II). Benveniste justifica tal título no prefácio de PLG I: "Se os apresentamos (os estudos reunidos no volume) sob a denominação de problemas isso se deve ao fato de trazerem em conjunto, e cada um em particular, uma contribuição ao grande problema da linguagem".

Ainda Dessons (2006) afirma ser a significação o ponto de vista fundamental a todos os estudos de Benveniste, agrupando-os em um mesmo projeto global. Atestam tal afirmação as palavras do próprio linguista sobre essa natureza essencial da significação: "[...] ela (a relação forma-sentido) nos coloca no centro do problema mais importante, o problema da significação. Antes de qualquer coisa, a linguagem significa, tal é seu caráter primordial, sua vocação original que transcende e explica todas as funções que

1 « Chez Benveniste, l'art du penser, c'est d'abord l'art du problème. » (DESSONS, 2006, p. 10). 
ela assegura no meio humano" (BENVENISTE, 1974/2006, p. 222). Teixeira e Messa (2015, p. 104) transcrevem fragmento de uma carta disponível na Biblioteca Nacional da França, em que o próprio Benveniste ratifica tal ponto de convergência de sua diversificada produção:

[...] Todas as pesquisas que fiz nesses últimos anos e o projeto que criei têm em vista o mesmo propósito. [...] Em resumo, minha preocupação é saber como a língua "significa" e como ela "simboliza". As tendências atuais de uma certa escola de linguistas querem analisar a língua sobre a base da distribuição e das combinações formais. Parece-me que é tempo de abordar com métodos novos o conteúdo dessas formas e ver segundo quais princípios ele é organizado. (BENVENISTE, apud BRUNET; MAHRER, 2011, p. 35).

É assumindo a significação como problemática central de sua reflexão sobre a linguagem que Benveniste desenvolve suas concepções de língua, de cultura e da relação entre elas, noções que balizam a teorização sobre aquisição da linguagem e as análises produzidas sobre as relações enunciativas criança-outro neste artigo. Assim, inscrevendo-se no quadro epistemológico da Teoria da Enunciação Benvenistiana (2005; 2006) e da Teoria Enunciativa da Aquisição da Linguagem de Silva (2007; 2009), o presente trabalho propõe-se a responder a duas questões, uma de caráter geral e outra de caráter específico: 1) como a criança, em seu ato de aquisição da linguagem, apropria-se das noções culturais de sua língua materna? 2) como a criança, em seu ato de aquisição da linguagem, elabora a significação do susto enquanto fato de cultura constitutivo da sociedade humana?

A partir do dispositivo teórico-metodológico (eu-tu/ele)-ELE, o qual comporta a criança (eu), o outro de seu convívio $(t u)$, a língua (ele) e a cultura (ELE) instanciados no ato de aquisição da linguagem, são analisados três fatos enunciativos de uma criança acompanhada longitudinalmente dos onze meses aos três anos e quatro meses, publicados por Silva $(2007 ; 2009)$. Em cada um desses fatos, observamos como a noção de susto é construída linguístico-enunciativamente enquanto símbolo cultural atrelado ao mundo dos homens, em geral, e ao mundo das crianças, em particular.

Perseguindo tais objetivos, estruturamos este estudo em quatro seções, além dos apontamentos iniciais e finais: inicialmente, a partir dos postulados enunciativos benvenistianos, teorizamos sobre a língua e a cultura como mecanismos de significação (cf. seção 2); em seguida, refletimos sobre a apropriação de noções culturais pela criança como uma experiência de significação na língua-discurso (cf. seção 3); na sequência, considerando os princípios enunciativo-aquisicionais desenvolvidos por Silva (2007; 2009), discutimos o lugar da intersubjetividade, da referência e da cultura no ato de aquisição da linguagem (cf. seção 4); posteriormente, apresentamos a metodologia (cf. seção 5) e a análise dos fatos enunciativos de linguagem selecionados nesta investigação (cf. seção 6).

\section{Língua e cultura: mecanismos de significação}

A discussão sobre língua e significação está na base da reflexão sobre linguagem de Benveniste. A linguagem, indissociável do homem, possui uma natureza simbólica atrelada à sua propriedade de significar. Essa propriedade de significação manifesta-se nas línguas na articulação forma-sentido em todas as unidades linguísticas. No entanto, 
muitos linguistas reduzem o estudo da língua unicamente à forma: "O que não se tentou para evitar ou expulsar o sentido? É inútil: essa cabeça de Medusa está sempre aí, no centro da língua, fascinando os que a contemplam" (BENVENISTE, 1966/2005, p. 135). Com efeito, o problema da relação forma-sentido persegue toda a linguística moderna, especialmente a benvenistiana. Ainda que a problemática da significação perpasse todos os trabalhos do teórico, dos comparatistas aos de linguística geral, ela é tema central dos artigos A forma e o sentido na linguagem (1966) e Semiologia da língua (1969).

No texto de 1966, tomando como gêmeas as noções de forma e sentido, Benveniste distancia-se de uma abordagem que as conceba em termos meramente opositivos e reinterpreta essa oposição no quadro da língua em uso. Para ele, a antítese forma/sentido contém o ser mesmo da linguagem, seu caráter primordial, que não é senão a significação, base de todas as realizações humanas, individuais e coletivas, ligadas ao exercício do discurso. Mas como a linguagem, atividade significante por excelência, significa?

Benveniste postula dois modos de significância linguística, duas maneiras de ser língua no sentido e na forma. No modo semiótico, cuja unidade é o signo e cuja função é significar, a forma vincula-se à relação opositiva entre signos no universo intralinguístico e o sentido, à sua existência no uso. $\mathrm{O}$ signo tem valor sempre genérico e conceptual, definindo-se por relações que se estabelecem intralinguisticamente, mediante distinção dos demais signos do sistema. O domínio semiótico é imanente, fechado em si mesmo e desprovido de referência; é o terreno da Linguística saussuriana, assentada sobre o princípio único do signo, de maneira que Benveniste declara: "Compete-nos ir além do ponto a que Saussure chegou na análise da língua como sistema significante" (BENVENISTE, 1974/2006, p. 224).

Essa tentativa de ir além se apresenta como o modo semântico, cuja unidade é a palavra e cuja função é comunicar, e no qual a forma corresponde ao sintagma, isto é, a palavra em emprego na frase, e o sentido, à ideia expressa pela frase através do agenciamento de palavras. A palavra, o signo atualizado no uso, tem valor sempre particular e circunstancial, definindo-se por uma relação sintagmática que implica referência à situação de discurso e à atitude do locutor. Em $A$ forma e o sentido na linguagem, a referência de uma frase é definida como "o estado de coisas que a provoca, a situação de discurso ou de fato a que ela se reporta e que nós não podemos jamais prever ou fixar" (BENVENISTE, 1974/2006, p. 231).

Enquanto o domínio semiótico diz respeito a uma propriedade da línguasistema, na qual a referência está ausente, o domínio semântico caracteriza-se como uma atividade da língua-discurso, do locutor que coloca a língua em ação necessariamente para referir acontecimentos e a sua experiência dos acontecimentos e possibilitar ao outro correferi-los:

A noção de semântica nos introduz no domínio da língua em emprego e em ação; vemos desta vez na língua sua função mediadora entre o homem e o homem, entre o homem e o mundo, entre o espírito e as coisas, transmitindo a informação, comunicando a experiência, impondo a adesão, suscitando a resposta, implorando, constrangendo; em resumo, organizando toda a vida dos homens. É a língua como instrumento da descrição e do raciocínio. Somente o funcionamento semântico da língua permite a integração da sociedade e a adequação ao mundo, e por consequência a normalização do pensamento e o desenvolvimento da consciência. (BENVENISTE, 1974/2006, p. 229, grifos nossos). 
Esses dois domínios - o semiótico e o semântico - não se opõem, mas se superpõem no funcionamento da língua: primeiro, a base semiótica, organizada intralinguisticamente por signos em relação segundo o critério da significação (o valor genérico e conceptual do signo no interior do sistema); segundo, a semântica construída pela língua-discurso na sintagmatização das palavras e conforme o critério da significação intencionada (o querer-dizer do locutor que atualiza linguisticamente o seu pensamento). Mas, como bem diz Benveniste (BENVENISTE, 1974/2006, p. 234), por trás desses dois domínios e "no fundo de tudo está o poder significante da língua, que é anterior ao dizer qualquer coisa".

Se em A forma e o sentido na linguagem (1966), Benveniste busca tratar das duas maneiras de ser língua no semiótico e no semântico, em um tratamento das noções mais voltado para preocupações linguísticas, em Semiologia da língua (1969), opera um alargamento de tais noções com uma preocupação semiológica. Por isso, lembramos com Silva (2016, p. 19) o fato de que "o problema da significação tem desdobramentos em várias dimensões na obra de Benveniste", que nesse texto nomeia a maneira específica de a língua significar de dupla significância da língua, característica que a torna a organização semiológica por excelência, pois o fato de comportar a significância dos signos (modo semiótico) e a significância da enunciação (modo semântico) faz dela o sistema interpretante de todos os outros sistemas semiológicos, inclusive de si própria. Essa é a semiologia da língua, a capacidade de a língua interpretar a si e aos demais sistemas, os quais "têm uma significância unidimensional: ou semiótica (gestos de cortesia; mudras), sem semântica; ou semântica (expressões artísticas), sem semiótica" (BENVENISTE, 1974/2006, p. 66, grifo do autor) - diferentemente da língua, cuja significância articula-se em duas dimensões, a dimensão do signo, a de ser reconhecido, e a dimensão do discurso, a de ser compreendido.

A centralidade da língua dentre os sistemas de signos deve-se também ao fato de ela: a) manifestar-se pela enunciação e referir uma situação dada, já que falar é sempre falar de - ou seja, a língua é convertida em discurso "para dizer alguma coisa, para transmitir uma mensagem" (BENVENISTE, 1974/2006, p. 20) - destaca-se aqui a questão da referência; b) compor-se formalmente de signos em relação, isto é, por apresentar uma "composição em unidades de significância" (BENVENISTE, 1974/2006, p. 52), distribuídas e integradas em níveis - destaca-se aqui a relação forma-sentido; c) ser produzida e recebida por membros de uma comunidade que compartilham os valores de referência dessa comunidade, pois "[a] linguagem tem sempre sido inculcada nas crianças pequenas, e sempre em relação ao que se tem chamado as realidades que são realidades definidas como elementos de cultura" (BENVENISTE, 1974/2006, p. 24) - destaca-se aqui a questão da cultura; d) ser a única atualização da comunicação intersubjetiva, já que "cada um se determina como sujeito com respeito ao outro ou a outros" (BENVENISTE, 1974/2006, p. 101) destaca-se aqui a questão da intersubjetividade.

É a capacidade de semiotização da língua que a torna interpretante de sistemas linguísticos/não-linguísticos e da sociedade. No que concerne à última, o linguista defende que a relação semiológica língua-sociedade é de inclusão da sociedade pela língua; uma relação englobante, em que a língua inclui a sociedade com a sua cultura. Por isso, quando trata do domínio semântico em Estruturalismo e linguística, Benveniste (1974/2006) trata de contextos e circunstâncias e conclui que esse domínio conduz à cultura, concebida como sistema de valores herdados via língua, pois defende 
ser "a língua reveladora da cultura" (BENVENISTE, 1974/2006, p. 23). E discute tal questão à luz da problemática da aquisição: "A linguagem tem sempre sido inculcada nas crianças pequenas, e sempre em relação ao que se tem chamado as realidades definidas como elementos de cultura, necessariamente"' (BENVENISTE, 1974/2006, p. 24).

A consideração da cultura como valores da sociedade transmitidos via língua já havia sido tematizada pelo linguista em textos anteriores aos artigos Semiologia da língua e Estruturalismo e linguística, como atesta a discussão estabelecida em Vista d 'olhos sobre o desenvolvimento da linguística:

\begin{abstract}
A cultura define-se como um conjunto muito complexo de representações, organizadas por um código de relações e de valores: tradições, religião, leis, política, ética, artes, tudo isso de que o homem, onde quer que nasça, será impregnado no mais profundo da sua consciência, e que dirigirá o seu comportamento em todas as formas da sua atividade, o que é senão um universo de símbolos integrados numa estrutura específica e que a linguagem manifesta e transmite? Pela língua, o homem assimila a cultura, a perpetua ou a transforma. (BENVENISTE, 1966/2005, p. 32, grifos nossos).
\end{abstract}

Nessa perspectiva, todo mecanismo cultural é um mecanismo simbólico, sendo o fundamento de tudo o simbolismo da língua como poder de significação, que age como "uma semântica que atravessa todos estes elementos de cultura e que os organiza" (BENVENISTE, 1974/2006, p. 25). Essa semântica transversal à cultura e organizadora de seus elementos engloba a sociedade e configura-a, instaurando o que Benveniste chama de semantismo social, manifestado principalmente no vocabulário, que "conserva testemunhos insubstituíveis sobre as formas e as fases da organização social, sobre os regimes políticos, sobre os modos de produção que foram sucessiva e simultaneamente empregados etc." (BENVENISTE, 1974/2006, p. 100).

Outra característica dessa faculdade semântica apontada pelo linguista é o duplo funcionamento intersubjetivo e referencial do discurso, assegurado pela língua, que distingue o eu do não-eu, sendo uma "realidade supra-individual e coextensiva à toda a coletividade" (BENVENISTE, 1974/2006, p. 101). Isto é, a língua é o que melhor permite a distinção entre indivíduo e sociedade, o que faz principalmente através dos chamados pronomes pessoais, no interior dos quais há uma dupla oposição: a oposição do $e u$ ao $t u$, estrutura de alocução pessoal exclusivamente inter-humana (funcionamento intersubjetivo), e a oposição do sistema eu/tu a ele, que possibilita a referência ao mundo externo à alocução (funcionamento referencial).

Esse duplo funcionamento discursivo diz respeito à integração do homem à cultura que o cerca e que atribui à sua vida forma, sentido e conteúdo, pois é na relação com o outro (intersubjetividade) que o locutor se funda como sujeito (subjetividade) e se torna capaz de reproduzir discursivamente acontecimentos e experiências (referência), possibilitando ao alocutário recriar pelo seu discurso tais vivências (coreferência), ambos produzindo sentidos a partir de normas e representações sociais (cultura).

Conforme Benveniste, assim como o sistema linguístico, o sistema cultural distingue o que tem e o que não tem sentido, consistindo "numa multidão de noções e de prescrições, e também em interdições específicas; o que uma cultura proíbe a caracteriza tanto quanto aquilo que prescreve" (BENVENISTE, 1966/2005, p. 32, negrito nosso, itálico do autor). É nessa linha argumentativa que o teórico defende que o 
homem não nasce na natureza, mas na cultura, e que toda criança aprende com a língua os rudimentos de uma cultura, não sendo nenhuma língua separável de uma função cultural. Como todos os elementos culturais derivam da articulação entre valores que se imprimem na língua, esta é reveladora da cultura na medida em que carrega consigo uma série de dados simbólicos.

Tanto a língua quanto a cultura empregam aparatos de símbolos específicos a cada sociedade. O símbolo, portanto, é o elo vivo que prende o homem, a língua e a cultura em uma relação humana de integração necessária. Se "encontram-se os problemas da análise da língua, de um lado, da cultura de outro, e os da 'significação', que lhes são comuns" (BENVENISTE, 1966/2005, p. 15), se todo mecanismo cultural é um mecanismo simbólico e se a cultura deixa sua impressão na língua, então a significação das formas da língua carrega os valores simbólicos da cultura à qual essa língua se vincula. Por isso, o sentido das unidades do domínio semiótico, por consistir no uso que fazem delas os falantes de uma determinada sociedade, está impregnado dos valores culturais dessa sociedade. Quando a língua é atualizada em discurso, o locutor carrega esses valores para o domínio semântico em um movimento singular de “adequação ao mundo" (BENVENISTE, 1974/2006, p. 229).

À luz da reflexão benvenistiana sobre língua, cultura e significação, podemos melhor pensar sobre nosso objeto neste estudo: a apropriação de noções culturais pela criança.

\section{A apropriação de noções culturais pela criança: uma experiência de significação na língua-discurso}

Considerar que o tornar-se falante de uma língua não é um processo instintivo nem uma faculdade natural, mas a apropriação do mundo do homem por meio da língua, com o conjunto de dados que ela traduz (BENVENISTE, 1974/2006), implica refletir sobre a relação língua-pensamento, pois este "não pode se materializar a não ser na língua e uma língua [...] não tem outra função a não ser 'significar"” (BENVENISTE, 1966/2005, p. 69).

Em Categorias de pensamento e categorias de língua (1958), Benveniste examina as relações entre língua e pensamento, partindo do princípio de que, "por mais abstratas ou particulares que sejam as operações do pensamento, recebem expressão na língua" (BENVENISTE, 1966/2005, p. 68) e reitera ser a forma linguística "não apenas a condição de transmissibilidade mas primeiro a condição de realização do pensamento" (BENVENISTE, 1966/2005, p. 69). Assim, a língua não é apenas a expressão do pensamento, mas a sua condição mesma: sem a forma linguística, o conteúdo mental não é senão "obscura volição, impulso que se descarrega em gestos, mímica" (BENVENISTE, 1966/2005, p. 69), de modo que o pensável é delimitado e organizado pelo dizivel. Nesse sentido, antes de atualizá-lo linguisticamente e torná-lo transmissível na comunicação, a língua é o que faz existir o pensamento, captável somente quando já adequado aos seus quadros.

Com esses argumentos, o linguista defende, no artigo, a tese de que as categorias do pensamento são determinadas pelas categorias da língua. Como ocorre essa determinação? Ora, neste texto, Benveniste não chega a uma resposta explícita, mas podemos defender, a partir da reflexão apresentada na seção anterior, que é no domínio da língua em ação e emprego, em sua função mediadora, que a língua possibilita "a 
normalização do pensamento e o desenvolvimento da consciência" (BENVENISTE, 1974/2006, p. 229). Essa possibilidade de pensamento liga-se à faculdade de linguagem relacionada a uma língua enformada de significação, visto que "pensar é manejar os símbolos da língua" e, nesse caso, Benveniste inclui em sua reflexão o fato de que "o vôo do pensamento liga-se (...) às condições gerais da cultura, à organização da sociedade" (BENVENISTE, 1966/2005, p. 69).

A instauração da criança na significação das formas do modo semiótico da língua, com os valores culturais nelas impressos, é uma questão relacionada ao problema da aquisição da linguagem e ao modo como cada criança engendra ou "fabrica" a sua língua. Tal apropriação ou "fabricação" vincula-se à natureza simbólica da linguagem atrelada à propriedade de significação da língua, que engloba a sociedade com seus valores culturais. Como a língua com a sociedade é dada à criança, esta se instaura nos símbolos de sua cultura através da enunciação, por meio de movimentos de integração entre forma e sentido à medida que descobre que tudo tem um nome, inclusive ela própria, sendo tal descoberta o despertar da consciência do meio social em que vive e que, através da língua, constituirá sua individualidade no interior da coletividade. Portanto, pela língua, a criança assimila a cultura e os valores que a constituem como um sistema que também distingue os sentidos, sistema este interpretado pelo sistema linguístico.

Knack (2016) deriva da teorização benvenistiana sobre cultura e significação um entendimento de "noção como valores culturais que se instalam no centro da significação e que permitem, de um lado, reconhecer o que tem sentido ou não e, de outro, compreender qual é esse sentido" (KNACK, 2016, p. 69, grifos da autora). A base dessa definição encontra-se no texto Dom e troca no vocabulário indo-europeu (1951), no qual Benveniste analisa as palavras dom e troca como fatos de vocabulário cujas transformações estão atreladas às transformações das instituições sociais e das relações humanas que as envolvem, sendo, desse modo, testemunhos do semantismo social discutido na seção anterior.

Também influencia a definição de noções culturais de Knack (2016) o artigo Semiologia da língua, mais especificamente a discussão acerca das propriedades de reconhecimento, vinculada ao domínio semiótico, e compreensão, vinculada ao domínio semântico. Trata-se de propriedades ligadas à significação da língua em uso nas relações intersubjetivas mediadas pela cultura, as quais, no caso da aquisição da linguagem, são definidoras do modo como a criança instaura-se em dados de cultura, traduzidos pela língua que comparece em suas relações enunciativas com outros. Essa apropriação de noções culturais pela criança consiste em uma experiência de significação na línguadiscurso em que ocorre a "transformação simbólica dos elementos da realidade ou da experiência em conceitos" (BENVENISTE, 1966/2005, p. 29, grifo do autor). Nesse caso, interessa-nos refletir sobre como os elementos de cultura, impregnados na significação, convertem-se em pensamento para possibilitar a atualização sempre renovada da língua em discurso pela criança.

Dessa transformação simbólica, buscaremos dar um exemplo na análise dos fatos enunciativos que constituem o corpus deste estudo, mas antes apresentaremos os deslocamentos da Teoria da Enunciação para o campo da Aquisição da Linguagem.

\section{Intersubjetividade, referência e cultura na aquisição da linguagem}


Deslocar a teorização enunciativa de Benveniste para o campo da Aquisição da Linguagem requer adotar a noção de ato para conceber a aquisição da linguagem como a apropriação singular que cada criança faz de sua língua materna, na relação com outro, com a língua e com a cultura. Tais considerações encaminharam Silva $(2007 ; 2009)$ a produzir bases teórico-metodológicas, sintetizadas pelo dispositivo (eu-tu/ele)-ELE, para investigar a instauração da criança na linguagem em relações enunciativas: as relações diádicas $e u$-tu, eu/tu e (eu-tu)/ele e as relações trinitárias eu-tu/ele e (eu-tu/ele)$E L E$. Tais relações configuram as três operações enunciativas de aquisição da linguagem.

Na relação diádica $e u$-tu, a criança está em relação de dependência com outro, configurando a conjunção criança-outro. Na relação diádica eu/tu, a criança passa a distinguir-se do outro ao se assumir como pessoa subjetiva (eu) distinta da pessoa nãosubjetiva $(t u)$, estabelecendo com ele a disjunção criança/outro. As relações eu-tu (conjunção) e eu/tu (disjunção) configuram a operação de preenchimento de lugar enunciativo, na qual ocorre a passagem do preenchimento de lugar enunciativo a partir do outro para o reconhecimento que esse lugar provoca no outro. Ou seja, na díade conjunta $(e u-t u)$, a criança precisa ser convocada pelo outro a preencher um lugar na estrutura enunciativa, pois seu dizer está na dependência do dizer do outro; já na díade disjunta $(e u / t u)$, a criança passa a convocar o outro, ao reconhecer o efeito que suas enunciações provocam no outro.

Na relação diádica (eu-tu)/ele, a criança estabelece a relação mundo/discurso, em que as pessoas $e u$ e $t u$, presentes no discurso, distinguem-se da não-pessoa ele, ausente. A relação (eu-tu)/ele configura a operação de referência, na qual ocorre a passagem da atualização de uma referência mostrada para uma referência constituída na línguadiscurso. Dito de outro modo, a criança entra no simbólico da língua ao integrar forma e sentido na constituição de referência no discurso, estando essa integração, inicialmente, ancorada na situação enunciativa (referência mostrada), e, posteriormente, podendo ser criada no interior do próprio discurso (referência constituída).

Na relação trinitária eu-tu/ele, há a consolidação da estrutura enunciativa com o reconhecimento pela criança de si como locutor, do outro como alocutário e da língua como possibilidade de atualização discursiva. Na relação trinitária (eu-tu/ele)-ELE, há a constituição de duas alteridades, a do tu (alocutário) e a do ELE (cultura), em que a criança produz referências a partir de diferentes formas e mecanismos. As relações $e u$ tu/ele e (eu-tu/ele)-ELE configuram a operação de inscrição enunciativa da criança na língua-discurso, na qual ocorre a passagem de um uso discursivo de instanciação subjetiva por meio de funções e formas para um uso discursivo em que a enunciação constitui e é constituída por outra enunciação. Isto é, a criança apropria-se do aparelho formal da língua para construir o seu aparelho formal da enunciação, marcando a enunciação no enunciado através de recursos linguísticos que lhe possibilitam também constituir outras enunciações no interior da sua.

Através dessas três operações, Silva $(2007 ; 2009)$ mostra, na análise de dados longitudinais de uma criança acompanhada dos onze meses aos três anos e cinco meses, como se dá o ato singular de instauração da criança na linguagem. Os resultados da análise indicam que o locutor-criança produz "uma história de enunciações, por meio da qual constitui sua língua materna e o sistema de representações de sua cultura, estabelecendo-se, desse modo, como sujeito de linguagem" (SILVA, 2009, p. 286).

Nessa perspectiva, enunciação e aquisição são concebidas ambas como atos de instauração da criança na "dupla natureza profundamente paradoxal da língua, ao 
mesmo tempo imanente ao indivíduo e transcendente à sociedade" (BENVENISTE, 1974/2006, p. 97), pois, se o locutor-criança se apropria da língua para dela fazer um uso singular, ele também a herda. Assim, o que a criança aprende não é o desempenho de um conhecimento inato, mas o mundo do homem, de forma que "[a] apropriação da linguagem pelo homem é a apropriação da linguagem pelo conjunto de dados que se considera que ela traduz, a apropriação da língua por todas as conquistas intelectuais que o manejo da língua permite" (BENVENISTE, 1974/2006, p. 21).

A concepção enunciativa de aquisição da linguagem autoriza uma releitura da famosa e criticada definição benvenistiana de enunciação como ato individual de apropriação de língua: embora esse ato seja individual, ele carrega interpretações da cultura, a qual deixa seus traços no discurso do locutor que se apropria da língua para se enunciar e convocar o outro a também se enunciar. Logo, se a enunciação é um ato individual e social e se a aquisição da linguagem é um ato enunciativo, então a aquisição é também ela um ato individual e social, porque a criança se instaura singularmente numa língua atravessada pela cultura da sociedade em que é falada.

\section{Os fatos enunciativos de aquisição da linguagem: da teoria à metodologia}

Esta pesquisa adota uma metodologia enunciativa de cunho qualitativo, "não prevendo a homogeneização e a generalização dos usos linguísticos da criança, visto que os elementos da enunciação (tempo, espaço e sujeitos) determinam as escolhas linguísticas" (SILVA, 2009, p. 214, grifos da autora) e interpretativista, pois uma abordagem enunciativa "inclui o sujeito, sendo assim a enunciação é sempre única e irrepetível e cada análise da linguagem é única também, embora a organização do sistema da língua seja da ordem do repetível" (SILVA, 2009, p. 216).

Nessa perspectiva, os dados de aquisição analisados neste estudo são tomados como fatos enunciativos de linguagem que comportam traços da regularidade do sistema e da singularidade do uso. Trata-se de três fatos oriundos de um corpus de natureza oral, coletados, transcritos e publicados por Silva $(2007 ; 2009)$. A informante é uma menina, Francisca, de classe média, residente na região metropolitana de Porto Alegre, acompanhada pela investigadora, com quem mantém laços familiares (relação sobrinha-tia), dos onze meses aos três anos e quatro meses, em sessões quinzenais e mensais. Consiste, portanto, em um corpus de língua falada constituído em coleta do tipo longitudinal - ao longo de um período de tempo - e em situação naturalística - em atividades cotidianas em ambiente familiar (SCARPA, 2001).

A unidade de análise é o recorte enunciativo, "concebido como o espaço de discurso em que determinado tema é referido e co-referido na alocução" (SILVA, 2009, p. 219). O recorte enunciativo é um fato de linguagem em que o locutor-criança (eu) constitui e é constituído na esfera do diálogo, produzindo referências e sentidos no discurso junto do alocutário-adulto $(t u)^{2}$.

2 Silva (2009, p. 220-221) esclarece que, mesmo o adulto tomando a palavra e enunciando junto da criança nos recortes enunciativos, "uma teoria enunciativa da aquisição da linguagem parte da suposição de que o eu é sempre a criança, logo é ela que é tomada como ponto de referência”. 
As categorias de análise derivam das relações enunciativas estruturantes das três operações de aquisição da linguagem descritas na seção 4. São elas: as relações diádicas $e u$-tu e eu/tu (operação de preenchimento de lugar enunciativo via conjunção e disjunção); a relação diádica (eu-tu)/ele (operação de atribuição de referência via referência mostrada e referência constituída); as relações trinitárias eu-tu/ele e (eutu/ele)-ELE (operação de inscrição enunciativa da criança na língua-discurso via autoreferenciação e dupla enunciação).

As instâncias de análise são duas: de um lado, a enunciação como ato; de outro, a enunciação como discurso. A análise da instância acional focaliza as relações enunciativas diádicas e trinitárias delimitadas acima, a fim de "mostrar como ocorre a instanciação da intersubjetividade na linguagem, a conversão da língua em discurso e a atualização do sentido em palavras" (SILVA, 2009, p. 220). Já a análise da instância discursiva verifica "a produção de referências pelo locutor e de co-referência pelo alocutário, tratando, nesse jogo, das formas e mecanismos enunciativos agenciados pela criança" (SILVA, 2009, p. 220). Segundo Silva (2009), tratar a enunciação como ato e como discurso significa centrar a análise na semantização da língua, "com a conversão de estruturas enunciativas produzidas pela criança em estruturas da língua. Nessa trajetória de semantização, atestamos os movimentos de entrada da criança no semiótico, língua como sistema de signos" (SILVA, 2009, p. 220).

Para fins de sistematização, o quadro abaixo apresenta os aspectos metodológicos discriminados nesta subseção:

Quadro 1 - Sistematização do dispositivo metodológico-analítico

\begin{tabular}{|c|c|c|}
\hline UNIDADE DE ANÁLISE & CATEGORIAS DE ANÁLISE & INSTÂNCIAS DE ANÁLISE \\
\hline $\begin{array}{l}\text { Recorte enunciativo: } \\
\text { - Diálogo entre o } \\
\text { locutor-criança (eu) } \\
\text { e o alocutário-adulto } \\
(t u) \text {, sobre um dado } \\
\text { tema }(e l e), \text { mediado } \\
\text { pela cultura }(E L E) .\end{array}$ & $\begin{array}{l}\text { Relações diádicas: } \\
\text { • } \quad \text { eu-tu (conjunção); } \\
\text { • } \quad \text { eu/tu (disjunção); } \\
\text { • } \quad(e u-t u) / e l e \\
\quad \text { (referência). } \\
\text { Relações trinitárias: } \\
\text { • } \quad \text { eu-tu/ele (inscrição). } \\
\text { - } \quad(e u-t u / e l e)-E L E .\end{array}$ & $\begin{array}{l}\text { Enunciação como ato: } \\
\text { - Relações diádicas e } \\
\text { trinitárias. } \\
\text { Enunciação como discurso: } \\
\text { - Formas } \\
\text { mecanismos } \\
\text { produtores de refe- } \\
\text { rências e co-referên- } \\
\text { cias. }\end{array}$ \\
\hline
\end{tabular}

Fonte: elaborado pelos autores. 2009):

Quanto às convenções de transcrição, seguimos as propostas por Silva (2007;

Quadro 2 - Convenções utilizadas na transcrição dos fatos enunciativos analisados

\begin{tabular}{|l|l|}
\hline Episódio & $\begin{array}{l}\text { Indicação do nome da criança seguido da } \\
\text { sua idade (ano; meses. dias) no momento } \\
\text { da coleta. }\end{array}$ \\
\hline
\end{tabular}




\begin{tabular}{|c|c|}
\hline Participantes & $\begin{array}{l}\text { Indicação dos participantes com as três } \\
\text { letras iniciais de seu nome, que aparece } \\
\text { nos turnos de fala, e, entre parênteses, a } \\
\text { explicitação do tipo de familiaridade com a } \\
\text { criança. }\end{array}$ \\
\hline Situação & Indicação das circunstâncias da coleta. \\
\hline Com & $\begin{array}{l}\text { Indicação de comentários da situação ou } \\
\text { interpretações dos dizeres da criança. }\end{array}$ \\
\hline$(?)$ & Indicação de dúvida de transcrição. \\
\hline $\mathbf{X X X}$ & $\begin{array}{l}\text { Indicação de palavra ou frase não } \\
\text { compreendida pelo transcritor. }\end{array}$ \\
\hline Sublinhado & Indicação de tom descendente. \\
\hline MAIÚSCULAS & Indicação de tom ascendente. \\
\hline a) - - & Indicação de pausa curta. \\
\hline @@@ & Indicação de pausa longa. \\
\hline$[=]$ & $\begin{array}{l}\text { Indicação de eventos não-verbais e breves } \\
\text { explicações. }\end{array}$ \\
\hline / & $\begin{array}{l}\text { Indicação de interrupção brusca de alguma } \\
\text { palavra ou frase. }\end{array}$ \\
\hline$?$ & Indicação de entonação de pergunta. \\
\hline$!$ & Indicação de entonação de exclamação. \\
\hline ... & Indicação de turno de fala em suspenso. \\
\hline , & $\begin{array}{l}\text { Indicação de organização de turnos de falas } \\
\text { longos ou enumerações. }\end{array}$ \\
\hline Negrito & Indicação de segmentos focais da análise. \\
\hline
\end{tabular}

Fonte: elaborado pelos autores.

Relativamente às perguntas norteadoras da pesquisa, retomamos as questões postas na introdução deste artigo (cf. seção 1):

1) Questão de caráter geral: como a criança, em seu ato de aquisição da linguagem, apropria-se das noções culturais de sua língua materna?

2) Questão de caráter específico: como a criança, em seu ato de aquisição da linguagem, elabora a significação do susto enquanto fato de cultura constitutivo da sociedade humana?

Essas indagações, juntamente à unidade, às categorias, às instâncias analíticas e às convenções transcritoras elucidadas acima, nortearão a análise dos fatos enunciativos levada a cabo na próxima seção.

\section{6. "O Dudu me tutô": a apropriação da noção cultural de susto pela criança}

A finalidade desta seção é analisar três fatos enunciativos de Francisca, informante da pesquisa apresentada na seção anterior. Os fatos são rotulados como recortes enunciativos seguidos de números em ordem crescente: recorte enunciativo 1; recorte enunciativo 2; recorte enunciativo 3. Passemos a eles. 


\section{Recorte enunciativo 1}

Episódio: Francisca (1;2.22).

Participantes: EDU (irmão de 6 anos); PAI; MÃE (filmando); BET (irmão de 15 anos).

Situação: FRA brinca de assustar a família dentro de casa.

FRA: ah [= engatinhando e aproximando-se de EDU]

EDU: AI [ = pula como se estivesse assustado]

MÃE: Francista, assusta o Dudu, assusta.

PAI: assim ó [= mostra como FRA deve assustar o irmão] $\tilde{A} H$ [= faz o som de assustar]@XXX@XXX aqui ó [= pega o braço de EDU] ó @assusta o Dudu.@ ARRRR [= som para assustar]

EDU: XXX

Com: o irmão BET também senta na área, ao lado de FRA. Silêncio.

FRA: AAH [= olha para BET e grita, assustando-o]

BET: ÃAI [= cai para trás como se estivesse assustado]

FRA: AHH [= olha para o pai e grita, assustando-o]

BET: [ = riso $]$

FRA: AHH [= olha para BET e grita, assustando-o]

BET: ÃI [= vai para trás como se estivesse assustado]

FRA: [= risos] AH [grita com BET, assustando-o]

BET: $\tilde{A} \tilde{A} I$ [= encolhe-se como se estivesse assustado]

FRA: AH [= grita com o pai, assustando-o]

PAI: ai [ $=$ risos]

FRA: AH [= grita com BET, assustando-o]

BET: ai que susto!

Neste primeiro recorte, destacam-se as relações diádicas eu-tu e eu/tu, estruturantes da operação de preenchimento de lugar enunciativo. É o mecanismo da conjunção/disjunção que entra em funcionamento aqui: por meio de apelos e intimações do alocutário-mãe/pai, o locutor-criança é convocado a enunciar, a ocupar um lugar na estrutura enunciativa do diálogo familiar, assustando o irmão de seis anos. A criança atende ao chamado dos pais, mas assusta o irmão mais velho, que entra em cena logo após os pais a interpelarem.

As sucessivas atualizações em tom ascendente do fonema /a/, como em (1) "AH", (2) "AAH" e (3) "AHH", seguidas de ações não verbais, como os risos diante das reações dos adultos que fingem se assustar e os próprios gestos de assustar, indicam que FRA não só está cumprindo a ordem dos pais (aspecto conjuntivo) como também passa a perceber o efeito que suas emissões provocam nos outros de seu entorno (aspecto disjuntivo). Lançando mão da prosódia e da gestualidade como procedimentos acessórios da enunciação vocal (SILVA; STUMPF, 2012), a criança deixa de ser apenas convocada e começa a convocar o outro, voltando-se do irmão para os pais para também assustá-los e divertir-se com suas reações.

A noção de susto é referida pelos adultos através de formas verbais, como na ordem da mãe: "Francisca, assusta o Dudu, assusta", e de formas nominais, como nas 
exclamações do irmão: “ai que susto!". Embora não nomeie ela própria o ato, a criança já começa a elaborar a sua significação, pois compreende o sentido da forma imperativa produzida pela mãe, associando-o à atitude do pai, o qual mostra como ela deve assustar o irmão. Essa associação, que sugere o início da formação do símbolo e da apropriação do sentido da forma susto pela criança, é atestada pelas suas repetidas tentativas de assustar aqueles que a cercam. O assustar e o ser assustado surgem, neste recorte, como ações culturais demonstradas, de um lado, pelos familiares, que, ao simularem sustos para divertirem a criança, apresentam um hábito comum à relação adulto-criança (o adulto fazer graça para a criança rir), e, de outro lado, pela própria criança, que inicia um processo de constituição de uma representação do que seja assustar a partir da percepção do retorno que suas enunciações suscitam no outro.

\section{Recorte enunciativo 2}

Episódio: Francisca $(1 ; 05.15)$.

Participantes: CLA (babá), AVÓ e CAR (tia, filmando).

Situação: FRA está na casa da AVÓ. Inicialmente está na garagem da casa com um álbum, com bonecas e com o gato. Após janta. Depois, vai para dentro de casa e volta para a garagem.

Com: FRA está próxima ao gato.

FRA: XXX [= olhando para o gato]

AVÓ: XXX viu? Viu o gatu? Chama ele chama chama@ grita

FRA: nenê [= corre até um carrinho com uma boneca dentro] @ NENÊ [= olhando CAR]

CAR: hum?

FRA: nenê

CAR: tem nenê aí?

(...)

Com: abaixa-se e fica em silêncio, observando o gato. Após, levanta-se.

AVÓ: XXX.

FRA: au au [= apontando para o gato]

Com: silêncio.

CAR: dê o au au?

FRA: o AU AU

CAR: é? O au au?

FRA: au au [= volta a abaixar-se e observar o gato comendo]

CAR: o au au

FRA: o au au@AH [= assustando o gato]

Neste segundo recorte, é a operação de referência que se sobressai, com o estabelecimento da relação diádica $(e u$-tu)/ele. Ancorando-se na situação enunciativa e, portanto, produzindo uma referência mostrada, o locutor-criança nomeia referentes próximos mostrando-os: a boneca dentro de um carrinho e o gato da avó que está comendo na garagem. Tais referentes do mundo são sintagmatizados no discurso, respectivamente, através das formas "nenê" e "au au". Analogicamente, a criança 
designa a boneca como se fosse um neném e o gato como se fosse um cachorro, já que, ao referir-se ao felino, generaliza o uso da onomatopeia "au au" - relacionada, em português, ao latido de cães.

Esquecendo-se da boneca, o locutor-criança faz do gato a referência do discurso, reiterando a forma "au au" para nomeá-lo, ao mesmo tempo em que o aponta, como em (4) "FRA: au au [= apontando para o gato]". Um aspecto interessante da operação de referência emerge na sequência de turnos de fala criança-adulto que se sucede em (5) "CAR: dê o au au? / FRA: o AU AU / CAR: é? O au au? / FRA: au au [= volta a abaixar-se e observar o gato comendo] / CAR: o au au". Trata-se da produção simultânea de referências, pelo locutor-criança (pessoa subjetiva $e u$ ), e co-referências, pelo alocutário-adulto (pessoa não-subjetiva $t u$ ), na reiteração da forma "au au" como tema do discurso (não-pessoa ele). É a criança transformando o sentido em palavra (semantização), através da representação do mundo por um signo (simbolização), e entrando na língua como sistema organizado de signos (semiotização).

O fonema /a/ reaparece, neste recorte, em (6) "FRA: o au au @ AH [= assustando o gato]", como um significante que o locutor-criança recupera de sua história de enunciações para novamente associá-lo ao significado de susto, desta vez mirando o gato da família. Embora a ordem das operações enunciativas de aquisição da linguagem não seja cronológica, a hipótese da recuperação desse significante é plausível, na medida em que o recorte enunciativo 2 (em que FRA tem a idade de $1 ; 05.15$ ) é posterior ao recorte enunciativo 1 (no qual ela tem 1;02.22). O assustar parece figurar aqui como um ato simbólico ligado à cultura infantil e à curiosidade/estranhamento que as crianças costumam sentir em relação a animais domésticos. A importância das co-referências produzidas pelo locutor-adulto reside no fato de que é a sua escuta que "introduz a criança cotidianamente no mundo do símbolo" (SILVA; FLORES, 2015, p. 141).

\section{Recorte enunciativo 3}

Episódio: Francisca (2;05.23).

Participantes: CAR (tia, filmando) e AVÓ.

Situação: FRA está em casa de sua avó, conversando com CAR e a AVÓ.

CAR: ela tem uma coisa pra ti conta

FRA: o Dudu me tutô e e e daí eu fiquei a póta e daí eu eu fiquei choandu

AVÓ: foi? Qui cachorru nojentu

CAR: o Dudu mãe assustô ela na porta e ela ficô chorandu

AVÓ: o Dudu ti assustô?

FRA: é, eu eu fiquei medo vó

AVÓ: ah tem qui dizê pra eli não faz assim Dudu

(...)

FRA: eu eu fiquei choandu

AVÓ: tu chorô bastanti?

FRA: é, lá na minha casa

(...)

FRA: Dudu abiu póta ãh! [= entonação de susto]

AVÓ: é? E deu um sustu? 
FRA: deu@ Dudu abiu póta ãh! [= entonação de susto] bah [= bate com as mãos na parede]

AVÓ: o que qui tu vai dizê pru Dudu? Diz assim: Dudu a vó não gosta qui tu mi assusta@ diz pra ele bem assim a vovó não gosta

FRA: é tu tem dizê pa eie eu não eu não gósu

(...)

FRA: Dudu péga [fica acocorando-se] ãh [gemendo e levantando-se]

AVÓ: é? [= risos] assim qui ele faiz?

FRA: Dudu ati@ ica bóta maca

AVÓ: bota aquela máscara?

FRA: é

AVÓ: e aí dá aqueli sustu

FRA: é, dá um susu

Neste terceiro recorte, ganham relevo as relações trinitárias eu-tu/ele e (eutu/ele)-ELE, constitutivas da operação de inscrição enunciativa da criança na línguadiscurso, na qual o locutor-criança consolida a estrutura enunciativa, reconhecendo a si como locutor, o outro como alocutário e a língua como potência de discurso. É nessa terceira operação também que a criança constitui duas alteridades: com o tu (alocutário) e com o $E L E$ (cultura), valendo-se de variados instrumentos linguísticos para semantizar a língua e nela subjetivar-se. FRA enuncia sua posição de locutor de três modos, dos quais os dois últimos dialogam diretamente com nosso objeto: a) marcando-se no discurso via categoria de pessoa; b) instanciando a dupla enunciação via relato e projeção de ações; c) forjando o susto como fato de cultura.

A dupla enunciação é instanciada no discurso de FRA pelo seu relato à AVÓ do susto que o irmão lhe deu, como em (7) "o Dudu me tutô e e e daí eu fiquei a póta e daí eu eu fiquei choandu". A instanciação da dupla enunciação ocorre ainda via ação projetada, como em (8) "é tu tem dizê pa eie eu não eu não gósu", em que a AVÓ é falada por FRA, isto é, FRA fala como se fosse a AVÓ dirigindo-se ao seu irmão e repreendendo-o por tê-la assustado. Esses trechos de ações relatadas e projetadas mostram como a temporalidade já se tornou intralinguística no discurso da criança, ou seja, o presente já não é mais o único tempo nele marcado, mas, sendo um presente axial e gerador, funciona como um eixo a partir do qual são gerados o passado (discurso relatado) e o futuro (discurso projetado), temporalidades retrospectivas e prospectivas em relação ao presente. É, de fato, um jogo de formas e de sentidos complexo, pois implica a operação de mudanças instantâneas no quadro figurativo da enunciação e exige da criança a habilidade de um "malabarista" para lidar com a "dança" das categorias de pessoa, espaço e tempo nessa sobreposição de enunciações como em (9) "é, lá na minha casa", em que a casa de FRA passa de "aqui" da enunciação relatada a "lá" no relato enunciado e de espaço (aqui) do discurso anterior à não-pessoa (ele) do discurso atual.

O percurso iniciado por FRA nos recortes enunciativos 1 e 2, em que ela começa a elaborar a significação de susto, parece ser concluído neste terceiro recorte. Além de atualizar o fonema /a/ em (10) "Dudu abiu póta ãh! [= entonação de susto]", remetendo novamente a estrutura sonora ao ato de assustar, o locutor-criança nomeia o ato, como em (11) "o Dudu me tutô e e e daí eu fiquei a póta e daí eu eu fiquei choandu", por meio da forma verbal "tutô", e (12) "é, dá um susu", por meio da forma nominal 
"susu". Tais formas enunciativas, embora não pronunciadas com exatidão do ponto de vista fônico, são compreendidas como palavras no discurso pelo alocutário, que tenta ajustar a forma após (11) - "o Dudu ti assustô?" -, mas não faz o mesmo após (12), terminando por aceitá-las como formas da língua. A nomeação do ato de assustar pela criança revela "o processo dinâmico da língua, que permite inventar novos conceitos e por conseguinte refazer a língua" (BENVENISTE, 1974/2006, p. 21), transmutando a experiência em signos e possibilitando, pelo fundamento da abstração, a atribuição de um nome concreto a uma ação imaterial. Se, antes, a noção de susto era significada por aspectos suprassegmentais (prosódia, entonação, ritmo) e ações não verbais (gestos), agora é significada por unidades segmentáveis ("tutô" e "susu").

\section{7 . Apontamentos finais}

Como a criança, em seu ato de aquisição da linguagem, apropria-se das noções culturais de sua língua materna? Como a criança, em seu ato de aquisição da linguagem, elabora a significação do susto enquanto fato de cultura constitutivo da sociedade humana?

A apropriação da noção cultural de susto e da significação de assustar (assustar e ser assustado) é determinada, em cada fato enunciativo, pela operação de aquisição ao qual este pertence. O primeiro fato é determinado pelo efeito do preenchimento de lugares enunciativos na operação de intersubjetividade. Já o segundo fato é determinado pela nomeação relacionada a um duplo movimento de dizer-mostrar na operação de referência. Por sua vez, o terceiro fato é determinado pelo relato e pela projeção de ações pela criança na operação de sua inscrição enunciativa na língua-discurso.

Enquanto nos dois primeiros fatos o que está em jogo é o assustar, com o locutor-criança agindo sobre o outro por meio de recursos prosódicos e gestuais, no terceiro, o que está em jogo é o ser assustado, com a criança produzindo referências ao fazer renascer pelo seu discurso o acontecimento de ter sido assustada pelo irmão e a sua experiência desse acontecimento e possibilitando ao alocutário co-referir para recriar, também pelo discurso, esse acontecimento e essa experiência. As formas "tutô" e "susu" figuram aqui como substitutas da experiência, providas pelo simbolismo da linguagem enquanto "estrutura imaterial, comunicação de significados, substituindo os acontecimentos ou as experiências pela sua 'evocação"” (BENVENISTE, 1966/2005, p. 30).

Nesse processo de referência/co-referência, configuram-se duas alteridades, com o outro da alocução $(t u)$ e com o outro da cultura $(E L E)$, que convocam a criança a instanciar-se na enunciação e tomam suas formas enunciativas como dizeres produtores de sentido, "permitindo-lhe constituir-se como um sujeito de alocução para percorrer uma trajetória para encontrar a língua, enquanto laço social" (SILVA, 2009, p. 272). Dessa trajetória, demos um pequeno exemplo aqui, com o aparente percurso de FRA na elaboração da noção de susto. A teorização e a análise nos levam a acreditar que a criança aprende com a língua os rudimentos de sua cultura, imprimindo-os em seu discurso, sendo prova disso a apreensão do susto como um dos "valores constitutivos da sociedade humana enquanto fatos de cultura" (DESSONS, 2006, p. 43) ${ }^{3}$.

3 «[...] valeurs constitutives de la société humaine en tant que faits de culture.» (DESSONS, 2006, p. 43). 
Embora tenhamos analisado fatos enunciativos do português brasileiro, produzidos por uma criança específica, esse processo de apropriação de noções culturais parece-nos ser de natureza mais ampla da relação da criança com a linguagem. A esse respeito, são pertinentes as palavras de Benveniste: "A criança nasce em uma comunidade linguística [...]. A apropriação da linguagem pelo homem é a apropriação da linguagem pelo conjunto de dados que se considera que ela traduz, a apropriação da língua por todas as conquistas intelectuais que o manejo da língua permite." (BENVENISTE, 1974/2006, p. 20-21). Por isso, a "possibilidade do pensamento liga-se à faculdade de linguagem, pois a língua é uma estrutura enformada de significação e pensar é manejar os símbolos da língua" (BENVENISTE, 1966/2005, p. 80). É, portanto, na relação com o outro e com a cultura que a criança constitui a faculdade simbólica da linguagem, que torna possível a apropriação de noções/valores culturais como uma das experiências de significação nas quais a criança passa de não falante a falante de sua língua materna.

Este trabalho espera contribuir com as reflexões que se debruçam sobre a linguagem da criança, a qual, parafraseando Benveniste acerca da natureza humana, é ainda e cada vez mais um objeto a ser descoberto.

\section{REFERÊNCIAS}

BENVENISTE, Émile (1966). Problemas de Linguística Geral I. $5^{\text {a }}$ ed. Campinas: Pontes Editores, 2005.

BENVENISTE, Émile (1974). Problemas de Linguística Geral II. $2^{\mathrm{a}}$ ed. Campinas: Pontes Editores, 2006.

DESSONS, Gérard. Émile Benveniste, l'invention du discours. Paris: Éditions in Press, 2006.

INGRAM, David. First language acquisition. Cambridge: Cambridge University Press, 1989.

KNACK, Carolina. Por uma dimensão antropológica do discurso: as passagens do aluno nas instâncias de ensino. 2016. Tese (Doutorado em Estudos da Linguagem) - Instituto de Letras, UFRGS, Porto Alegre, RS.

SCARPA, Miriam Ester. Aquisição da linguagem. In: BENTES, Anna Chistina \& MUSSALIN, Fernanda. Introdução à lingüística: domínios e fronteiras. V. 2 São Paulo: Cortez, 2001.

SILVA, Carmem Luci da Costa. A instauração da criança na linguagem: princípios para uma teoria enunciativa em aquisição da linguagem. 2007. Tese (Doutorado em Estudos da Linguagem) - Instituto de Letras, UFRGS, Porto Alegre, RS.

SILVA, Carmem Luci da Costa. A criança na linguagem: enunciação e aquisição. $1^{a}$ ed. Campinas: Pontes Editores, 2009.

SILVA, Carmem Luci da C.; STUMPF, Elisa. O papel dos índices específicos e dos procedimentos acessórios na enunciação e na metaenunciação da criança. Desenredo. Revista do Programa de Pós-Graduação em Letras da Universidade de Passo Fundo, v. 8, n. 1, p. 115-143, jan./jun. 2012.

SILVA, Carmem Luci da Costa; FLORES, Valdir do Nascimento. A significação e a presença da criança na linguagem. Estudos da Língua(gem), Vitória da Conquista, v. 13, n. 1, p. 133-149, jun. 2015. 
SILVA, Carmem Luci da Costa. A conversão da língua em discurso: enunciar para significar. Antares: Letras e Humanidades, Caxias do Sul, v. 8, n. 15, p. 15-28, jan-jun. 2016.

TEIXEIRA, Marlene; MESSA, Rosângela Markmann. Émile Benveniste: uma semântica do homem que fala. Estudos da Língua(gem), Vitória da Conquista, v. 13, n. 1, p. 97-116, jun. 2015. 